\title{
BEYOND BOND MARKETS 2000: THE ELECTRONIC FRONTIER AND REGULATION OF THE CAPITAL MARKETS FOR DEBT SECURITIES
}

\author{
STEPHEN WALLENSTEIN*
}

I

INTRODUCTION

On October 18-19, 1999, more than fifty securities lawyers, representatives of ratings agencies, regulators, and academics gathered in Washington, D.C., for a conference on the regulation of capital markets for debt securities. The conference, generously cosponsored by the Bond Market Foundation and the Duke University Global Capital Markets Center, was organized by Executive Director Stephen Wallenstein of the Duke University School of Law and the Fuqua School of Business. The purposes were to examine the characteristics of debt capital markets and to assess the role of government policy and self-regulation on the operation of these markets. The program was organized around the following three topics:

\section{Distinctive Features of Debt Markets;}

2. Regulatory Issues Driven by Risk and Liquidity Considerations; and

\section{Technology and the Regulation of Debt Markets}

This article summarizes some of the recurrent themes and conclusions arising from deliberations by conference participants, and applies those themes and conclusions in an examination of issues concerning electronic markets that have emerged since the conference took place. We hope to move the debate beyond the existing regulatory framework, to consider how recent technological developments necessitate a new approach to the regulation of corporate debt transactions. In the process, we relied on a complete transcript of the proceedings, which omits the names of all participants in accordance with our agreement that remarks would go unattributed. This article represents a synthesis of the

Copyright @ 2000 by Stephen Wallenstein

This article is also available at http://www.law.duke.edu/journals/63LCPWallenstein.

* Executive Director, Duke University Global Capital Markets Center; Senior Lecturing Fellow, Duke University School of Law and Fuqua School of Business. 
stimulating and thoughtful ideas offered at the conference, and their application to the ever-dynamic debt capital markets of today.

\section{II}

\section{CORPORATE DEBT MARKETS AND SELF-REGULATION}

Empirically, corporate bond markets have been one of the most understudied areas of the economy, especially relative to other assets prevalent in American capital markets. This theme was prominent in the discussions, as participants repeatedly noted the paucity of data that would be the building blocks for research in this area. Reasons for this absence of information include lack of centralized reporting of trades, lack of transparency, and the relatively small size of the markets for exchange-traded bonds-a small fraction of the total market-which predominantly trade over the counter. Many conference participants echoed regulators' concern about the lack of information available to anyone other than dealers and their institutional clients.

The institutional nature of corporate debt markets complicates attempts to apply broad regulatory principles to this segment of the capital markets. Because institutions have substantial access to high-end advisory services, as well as the recommendations of ratings agencies, they are far more sophisticated and less vulnerable to misinformation than are retail investors. Because more than four million individual debt securities are currently outstanding in the United States, including government, corporate, municipal, mortgage, and asset-backed debt (versus approximately ten thousand equity securities), bond advisory and information services face a daunting task. This task is more difficult because trading in the vast majority of these debt securities is quite infrequent. Moreover, administrative and information services must account for a greater number of variables, such as time to maturity, coupon rate, and benchmark treasury rates. In addition, external factors-such as dealer inventory and the size of a purchase or sale in relation to the amount of that security outstanding-can have a serious impact on bond prices in ways that are incompatible with regulatory paradigms based on an equity-style approach.

Furthermore, institutions enjoy a superior pricing power with respect to their dealers, which allows them to purchase securities at lower bid/ask spreads. The size of their transactions should permit the more knowledgeable institutions to force dealers closer to the margin on large corporate debt purchases. The lack of transparency and reporting allows dealers to raise spreads beyond what a more transparent market would permit. Moreover, antiquated purchasing methods have defined corporate bond markets, even as their equity counterparts have modernized. Investors wanting to purchase a debt security have had no choice but to call individual dealers by phone to learn the dealer's price and inventory. Nothing guarantees that two investors would receive the same answer to that question. Despite these criticisms, however, the relatively closed nature of corporate debt markets appears to have served institutional in- 
vestors effectively because of their ability to shop for the best price, and simultaneously to extract liquidity information from potential dealers.

Liquidity, which is determined by several key factors, affects the desire of both dealers and investors to hold a given security. One of the major causes restricting the liquidity of corporate bonds is their limited client base. Because corporate bonds are relatively heavily taxed at both the federal and state levels, retail investors tend not to become major consumers of these instruments. This is unlikely to change absent significant changes in the tax code. Retail investor concern over asymmetric information, though of questionable justification, may also limit their participation. And, because retail investors trade securities more frequently than insurance companies and most pension funds, at least in the equities market, their absence may contribute to the relative illiquidity of debt markets. It should be noted, however, that retail bond investors predominantly buy and hold, instead of trade. In fact, because institutions, such as insurance companies, purchase corporate bonds to match their future liabilities, bonds are placed in portfolios where they remain until maturity. This is vastly different from equities, which are traded regularly on information about changes in the issuer. This crucial determinant of liquidity stems more from exogenous factors-such as the nature of institutional investors and their own objectives, and the tax laws-than from the microstructure of debt markets. Thus, attempts to increase liquidity must be sensitive to the different markets, types of issues, and the institutions participating in those markets.

III

\section{NEW Frontiers: ElECTRONIC TRADING AND CORPORATE DEBT MARKETS}

Currently, there are more than seventy online trading systems for debt securities, and in 1999, approximately six percent of fixed income trades occurred online. BusinessWeek estimates that thirty-seven percent of all bond trades will occur online by 2001. ${ }^{1}$ More significantly, Greenwich Associates reports that eighty percent of institutional investors are either already trading bonds online or considering doing so in the near future. ${ }^{2}$ This shift toward Internet trading will have a significant impact on the market for corporate debt instruments, as well as the regulatory framework applied to this market.

Electronic trading systems for fixed-income securities take several forms. Regardless of their particular form, each system causes the trading process for these instruments to be in line with electronic equity trading systems. There are three basic types of systems: (1) the auction or bidding systems, in which dealers and investors place direct bids on issues; (2) the secondary multi-dealer systems, in which institutional clients trade with dealers but not with other investors; and (3) the cross-matching systems, in which trades placed by both buyers and sell-

1. See Toddi Gutner, The e-Bond Revolution, BUSINESS WEEK, Nov. 15, 1999, at 270.

2. See Michael Casey, Fixed-Income Investors Turn to the Web to Trade, WALL ST. J., Feb. 9, 2000 , at B17. 
ers are matched anonymously. As systems evolve through consultation and beta-testing by dealers, they will likely converge into a unified platform that will offer multiple capabilities to traders who desire attributes of all three systems. ${ }^{3}$

By aggregating execution capability, financial information, and other services into a single platform, electronic systems are enabling both institutional and retail investors to conduct real-time transactions much more efficiently over the Internet. Perhaps most important, these systems allow investors to examine multiple debt offerings in a single location, whereas otherwise they would have to contact individual dealers. Investors can place an order electronically with their preferences, and receive bids either from dealers they select or from anyone holding inventory. Also, electronic interfaces provide users with the flexibility to screen issues according to their criteria, and to view them in comparison to benchmark U.S. treasuries, the swap curve, or other emerging benchmarks, which play a central role in corporate bond pricing.

Online trading systems have the potential to close the gap in services available to institutional buyers and retail investors. By providing price and availability information on a physical screen, investors can be confident that they are receiving the same information as others, thus perpetuating an expectation of transparency without formal regulation. Institutional investors have stated that they find the speed and convenience of electronic systems to be one of the more important benefits to online trading, rather than any resulting price transparency and tightening of spreads. Electronic trading systems increase their capacity to manage a larger portfolio, to do so more efficiently, and to complete more transactions than possible with existing dealer-based systems. The same technology also radically increases the speed with which dealers may refresh prices of a vast number of securities.

The features of online debt exchanges for corporate bonds can be designed to provide a wealth of benefits to both issuers and investors. Issuers can use these platforms to publish corporate information and to allow for real-time pricing of securities. They also allow full online negotiation as well as manually processed transactions. In addition, significant possibilities exist for issuers to broadcast and publish messages to institutional and other investors, mitigating the need to embark on costly and time-consuming roadshows for smaller offerings. Bloomberg and other existing Internet information providers already possess this capability. As trading systems advance, they will all provide these benefits, and will allow electronic information to replace physical offering documents currently mandated by regulatory institutions. As the industry moves toward T plus 1 and straight-through processing, these systems also hold the promise of significantly reducing back-office costs for both investors and dealers.

3. The most recent ETS survey has been posted on the Bond Market Association's website, where it will be continuously updated. See The Bond Market Association, BondMarkets. Com (visited Oct. 12, 2000) <http://www.bondmarkets.com>. 
Electronic systems also give issuers the option of issuing their own debt offerings directly to investors, instead of working through a broker. Large corporations such as Ford, General Electric, and General Motors have already taken advantage of this capability, replacing offerings they formerly handled by phone. These transactions have become increasingly feasible because of their relatively routine nature, because large corporations issue and refinance debt so frequently. Dealers, though initially skeptical of potential revenue losses, now appear to accept this outcome largely because of the razor-thin margins generated by large commercial offerings; dealer margins hover around $0.05 \%$, versus $7 \%$ for equity offerings. They will find that greater revenues can be generated by providing advisory services than by handling the sale of such routine securities.

Investors may benefit from the ability to view offerings from multiple issuers on a single screen that includes real time pricing, rates, and inventory. They will also retain the ability to negotiate with dealers for the best spread, as well as with the issuer on price and rate. Completing transactions electronically will also save on execution and costs. Electronic systems may also align with thirdparty entities to provide rating and other advisory services so that debt markets ultimately are more appealing to retail investors. If the market drives retail investors to an online platform, dealers will also benefit by having more time to spend with institutional buyers instead of on retail accounts, and still benefit from the liquidity these smaller buyers can provide at crucial times. Furthermore, electronic platforms can allow investors to gain significantly better returns than under the current physical systems. Because electronic platforms are likely to narrow the spread on issues, investors will enjoy a noticeable increase in their portfolio performance.

The emergence of electronic trading in the corporate debt markets will have several important effects on the larger financial system. First, by increasing the efficiency of the markets, U.S. dealers will be able to maintain a larger share of the world debt market. Presently, the rapid growth of debt markets in Europe threatens to cut into the U.S. share of overall offerings. Electronic platforms, however, have the potential not only to allow the United States to maintain its present market share, but also to attract new customers looking for the lowest costs and most complete information. This greater transparency may make fixed-income investing more attractive to various classes of investors, who might otherwise be deterred from participating in markets that they perceive as biased in favor of institutions. These developments could redound to the benefit of U.S. debt markets as well as the financial community generally.

Additionally, electronic systems may eventually provide a significant increase in overall market liquidity and lessen the risk of systemic shocks, such as those that occurred in late 1998. The liquidity crisis in debt markets in the aftermath of the Long Term Capital Management collapse has still not fully abated. By aggregating transactions in an electronic platform, all dealers and investors will, in times of distress, be able to locate each other more quickly. 
This prospect is similarly appealing to institutional investors, who complain about the decrease in dealer capital commitments, and the corresponding dearth of liquidity, since 1998. Retail investors also may be attracted by greater liquidity in smaller markets, where the vast majority of debt securities today may trade no more than once per year, if that often.

Still, there are limitations on the capability of these systems to replace completely the existing infrastructure for corporate bond trading. Smaller issuers may fear aftermarket retribution from dealers if they move their transactions to web-based systems and cut the dealers out of the transaction. This would occur if dealers were unwilling to commit capital by purchasing bonds in the aftermarket if they did not manage the deal and receive the fees that would have come with it. As a result, issuers would find lower demand for their offerings, which would depress prices enough to eliminate the savings accrued by managing the transaction online in the first place. Moreover, investors wanting to move large blocks of debt quickly will still require the presence of large dealers to place these orders without upsetting the equilibrium in the market and depressing the price. The success of electronic systems, both those founded by existing dealers and those founded by independent owners, will therefore hinge on their ability to interact efficiently with the existing infrastructure.

Online trading systems hold great potential for corporate debt markets. The realization of that potential depends largely on the success of dealers and issuers working with regulators to extend the self-regulatory principles of existing platforms to evolving electronic systems. It is crucial that efforts not be made to differentiate between online and offline markets. These two markets are rapidly converging, so that any regulatory action runs a serious risk of hindering their growth and efficiency. Any regulatory action would also discourage cooperation between dealers and other service and information providers, a necessary component of maturity in this market.

IV

\section{REGULATORY IMPLICATIONS}

The significant structural changes brought about by Internet trading platforms have important implications for efforts to regulate capital markets for corporate debt. Efforts to align debt markets more closely with their equity counterparts need to be reevaluated in the context of the trading environment. Regulators should generally seek to provide market participants with the flexibility to develop the most efficient offering and trading procedures allowed by technological innovation. Uncertainty is currently at a high point, and regulators must resist the temptation to manage this uncertainty with new restrictions on transactions or additional requirements for dealers.

Transparency concerns, one of the most critical areas of debate for the past decade, have been obviated as large dealers have moved to participate fully in online bond trading. Dealers have steadfastly challenged the details of government proposals for operational changes to facilitate corporate bond price 
transparency through dissemination of transaction reports to the public. But a new regime that accommodates at least some of the dealers' concerns about the impact on liquidity may be approved by the SEC in the near future. As the marketplace has brought a higher level of disclosure than was initially thought practicable, the relevance of this expected action is questionable. Dealer cooperation in the development of electronic platforms demonstrates their commitment to transparency, even though it may have negative results for them financially. Their continued collaboration will ultimately hinge on their right to continue to operate under self-regulation.

Ratings agencies and other third-party service providers will continue to play a vital role in transmitting information to investors. As dealers increasingly adapt their business models to provide high-end advisory services to institutional clients, more traditional functions will be left to other firms, who will in turn find a growing market for their services. Service providers will emerge to serve all classes of investors with the type of information most relevant to their investing needs, all facilitated by dealers' willingness to partner with online providers. Self-regulation will become more attractive for all parties, as newly transparent systems allow for more precise reporting and monitoring activity. Rules must be developed to ensure that information is made available in such a manner that it will not harm investors or dealers by divulging their positions too quickly, but still will allow fair access to transaction information.

Electronic systems provide the immediate benefit of increasing liquidity for all investors, thus narrowing spreads and making debt markets more accessible to retail investors. Issuers will soon find a larger market for their offerings, as more diverse investors are attracted to debt securities. More competition should also lead to more attractive prices. Because liquidity has long been a central goal of regulatory efforts, continuing self-regulation of markets as they migrate toward an electronic platform will best serve the goals of both issuers and investors.

The continued viability of self-regulatory organizations will provide important fuel for the growth of these electronic markets. The rise of third-party information providers, in addition to ratings agencies, will ensure democratic dissemination of information without regulatory interference. Today's trading networks must provide efficient execution and liquidity or they will not survive; the competitive nature of the market forces service providers to fight for customers with service and information, because spreads have narrowed, and fees have fallen to near zero.

Perhaps the most significant challenge to electronic debt markets lies in the future. While online platforms have been developed during strong economic times, we have yet to experience electronic trading in the context of a prolonged economic downturn. One can presume, though, that lessons from the liquidityinduced crisis of 1998 will ensure that dealers and investors alike will take advantage of the opportunity to centralize their operation in a single platform that provides extra security to all parties. Anonymous systems will eventually make 
it easier to test the market without divulging one's current holdings or desire to purchase; such discretion is a valuable opportunity in fragile markets.

Future uncertainty over dealer capital commitments also compounds attempts to predict the future of this market. Markets may evolve in such a way that sufficient volume provides liquidity without large commitments from dealers. This, however, may be seriously tested in more volatile times. The dealer's role in Internet-based markets will change drastically as margins continue to evaporate and spreads narrow to the point where it becomes unprofitable for dealers to enter the market on their own behalf. More likely, they will develop more specialized products to meet the financing needs of their issuer clients while simultaneously adopting a more advisory role with institutional investors. 